\title{
The Art and Business of Revitalizing a 50-Year-Old Science and Technology Magazine
} By the time you flip to this page you will have noticed there is
something dramatically different with Communications of the ACM.

The name on the cover remains the same, but even at first glance it is clear that the differences far outweigh the similarities with what we can now fondly and lovingly refer to as the old CACM.

Every decade or so, it is common for magazines to reinvent themselves. This is the case for many reasons, some related to the publishers and the changing dynamics of the publishing industry and some related to changing market and readership demographics. Very few magazines are able to survive over time without reacting to these changes and Communications of the ACM is no exception. In fact, magazines in the technology sector are even less immune to such changes, because of the rapid growth of the industry as a whole and trend toward specialization. As new areas of research and technology emerge, new publications are launched to satisfy the information needs of those new communities. The number of new technology magazines launched over the past 10 years for this reason is startling, each carving out a highly targeted and dedicated niche.

Equally startling is the number of technology magazines that have folded or merged into other publications over the past two years. As many magazines are heavily dependent on advertising revenue to fund operations, recent economic conditions and the rapid migration of advertising revenue from print to online have had a sobering effect on the technology magazine publishing industry.

Publications that have the ability to transform themselves editorially and appeal to the changing needs of their readership have the greatest ability to succeed. Publications that can thrive even under these adverse market conditions are truly exceptional.

For 50 years, Communications has stood the test of time and when necessary reinvented itself to keep pace with ACM's diverse and growing membership and with the leadership of the computing field. In recent years, the computing community has started to indicate to ACM's leadership that it was time for a changeperhaps even a dramatic one-for the flagship publication.

The ACM membership has consistently grown more diverse over the past decade and its information needs have grown more demanding. No longer is it possible to categorize ACM's membership into a few distinct buckets, such as Educator or Researcher or Practitioner. Such distinctions make sense on paper and are favorable for commercial reasons, but they are also extremely limiting and do not reflect the way things often work in the real world, where these lines are often less defined. Practitioners are in fact interested in what next-generation research is coming down the pipeline, researchers are of course interested in what major technology challenges exist, and both groups have a vested interest in issues related to computing education. But as publishers it is far too easy to draw the distinctions instead of the similarities and to produce publications that target specific categories of readers instead of large and diverse communities that share common goals and interests.
When the field of computing was in its infancy, Communications of the ACM was created to serve as a single source of highquality authoritative information to help bring together a growing community of scientists, technologists, and educators by highlighting the best the field had to offer. Some 50 years later, even though the field has grown tremendously, it continues to experience growing pains, and now more than ever requires a revitalized publication to bring this community together. The new Communications of the $A C M$ is in many ways a homecoming for the field of computing itself and an opportunity to help guide the field through what many believe is a critical stage in the field's maturation into adulthood.

Over the coming months, Communications' dynamic new Editor-in-Chief, Moshe Y. Vardi, an all-star lineup of contributors, and I will introduce you to more of the innovations that form the basis for the new Communications. But it is most important to note that all of the changes to this new vision reflect the best the international computing community has to offer.

The true innovation, however, lies in the expansion of the magazine's editorial scope, which will appeal to the community's diverse mix of researchers, practitioners, and educators in all areas of computing and information technology.

It is with great pride and appreciation for your continued support of ACM's flagship publication that I welcome you to the new Communications of the ACM.

Scott E. Delman, GROUP PUBLISHER 